\title{
Cristianos nuevos en la Audiencia de Santa fe, Popayán y Tierra Firme, entre los siglos XVI y XVII Entre la aceptación y el rechazo*
}

\author{
Por María Cristina Navarrete
}

\section{Resumen}

La presencia de grupos humanos en los reinos de Indias de procedencia diferente a la española durante el período colonial ha sido poco estudiada. Asimismo, los investigadores apenas empiezan a desarrollar estudios con enfoques diferentes a la legislación y las instituciones, y a reconocer la validez de la historia cultural y social, con respecto a la configuración de las sociedades coloniales en su diversidad y en las formas como se organizaron. Desde tal perspectiva, este artículo propone el estudio de los cristianos nuevos portugueses que se asentaron en las provincias de la Audiencia de Santa Fe, Popayán y Tierra Firme, en la segunda mitad del siglo XVI y el XVII.

\section{Palabras claves}

Converso, sefardita, cristiano nuevo, criptojudío, Inquisición, pureza de sangre.

\begin{abstract}
The presence of peoples who inhabited the Kingdoms of the Indies during the Colonial period who were not of Spanish origin has received very little scholarly attention. In the past research was focused on legal and institutional issues. The new research seeks to validate the understanding of the social and cultural aspects of societies in Colonial times in terms of organization and diversity. The purpose of this article is to study the Portuguese New Christians who settled in the Audience of Santa Fe, Popayán and "Tierra Firme" in the second half of the sixteenth and during the seventeenth centuries.
\end{abstract}

\section{Key words}

Convert, Sephardic, New Christian, cryptojew, Inquisition, blood purity.

\section{Antecedentes históricos}

\footnotetext{
* Artículo tipo 1: de investigación científica según Colciencias. Este artículo está relacionado con el libro La diáspora judeoconversa en Colombia siglos XVI y XVII. Incertidumbres de su arribo, establecimiento y persecución, resultado de una investigación de mayor envergadura sobre los cristianos nuevos portugueses arribados a Colombia en el primer período colonial. Para el logro de la investigación se tuvo el soporte de la biblioteca John Carter Brown, de la Universidad de Brown, en Providence, Estados Unidos, mediante el auspicio de la Touro National Heritage; la Escuela de Estudios Hispano-Americanos de Sevilla y el Instituto Colombiano de Antropología e Historia de Bogotá, con el apoyo para investigación en historia colonial.

${ }^{* *}$ Doctora en Filosofía y letras (sección de Historia) Universidad complutense de Madrid. Profesora titular (jubilada) Universidad del Valle. Email: manavarr@emcali.net.co.
} 
Es común pensar que los grupos que configuraron étnica y culturalmente el pueblo colombiano fueron los españoles, los indígenas y los africanos. Aunque es verdad que hubo restricciones a la entrada de extraños de la corona española a los reinos de Indias, durante el período colonial --en diversas circunstancias y aprovechando resquicios-- llegaron a la Audiencia de Santa Fe, a la provincia de Popayán y a Tierra Firme, extranjeros procedentes de otras regiones. Algunos se valieron de condiciones políticas favorables de España internamente o con reinos rivales, y otros llegaron contraviniendo la legislación. Estos caminos fueron utilizados por los "cristianos nuevos"1, también llamados "conversos", especialmente portugueses, descendientes de antiguos judíos sefarditas" a quienes les estaba prohibida la permanencia en las Indias por considerarlos extranjeros y por la sospecha de practicar clandestinamente la herejía judaizante. Si bien no es posible afirmar con certeza que todos los portugueses que llegaron al Nuevo Reino de Granada eran descendientes de judeoconversos, es factible pensar que la gran mayoría lo fue. El haber abandonado la Península para buscar rincones donde no había la Inquisición o se creía que ésta era menos beligerante; contar con antepasados castigados por el Santo Oficio ibérico, y el tipo de oficios desempeñados en los lugares de supuesto refugio, permiten lanzar la hipótesis y apoyar la creencia de los siglos XVI y XVII de que ser portugués era sinónimo de converso y potencialmente judaizante.

El estudio de estos siglos, particularmente en las provincias de lo que luego sería el virreinato de la Nueva Granada, apenas comienza a cobrar interés. Son escasas las investigaciones que abarcan estas centurias, limitación que obliga a indagar la presencia de grupos peninsulares, de alguna manera marginales, como aquellos sujetos de ancestro hebreo, especialmente portugueses, cuyo establecimiento y desenvolvimiento socio-económico y cultural data de la segunda mitad del siglo XVI y el XVII. La conversión obligada de sus antecesores, tanto en España como en Portugal, los transformó en "cristianos nuevos" o "conversos". La existencia de estas comunidades también fue un fenómeno histórico propio del virreinato de México y del Perú, de las provincias argentinas y las principales regiones de Brasil en los siglos coloniales.

La historia cultural sirvió como sustento teórico para el desarrollo de la investigación sobre los cristianos nuevos y de la cual deriva este artículo. Su importancia radica en que los objetos de análisis exceden lo que anteriormente se llamó alta cultura, y revisa creaciones humanas previamente consideradas de menor valía; por ello la historia cultural posibilita el estudio de las elaboraciones singulares y comunitarias de la vida de los judeoconversos que se dispersaron por las gobernaciones adscritas a la Audiencia de Santa Fe, especialmente en la provincia de Cartagena. También la historia social tuvo validez esencial para

\footnotetext{
${ }^{1}$ Por cristiano nuevo se entendía el judío recién convertido al cristianismo y toda su descendencia, el término es sinónimo de converso. Los españoles utilizaron con más frecuencia la palabra converso y los portugueses cristiano nuevo.

${ }^{2}$ Sefardita viene de Sefarad, nombre que en la tradición hebrea se daba a Iberia.
} 
comprender la formación de las sociedades coloniales, su diversidad y las estrategias de organización de los colectivos marginales ${ }^{3}$ (Navarrete, 2010, p. 19).

Indagar sobre la presencia de los conversos en el Nuevo Mundo implica observar los acontecimientos relacionados con el proceso histórico que los condujo a la América española. Es preciso recordar que en 1492 la corona española expidió el edicto de expulsión de los judíos de su territorio y les dio cuatro meses para aceptar el bautismo o vender sus bienes raíces y abandonar el país. Como la salida de dinero en metálico estaba prohibida, la única opción era convertirlo en letras de cambio, lo que hizo que muchos se hicieran bautizar a última hora. A éstos y a los convertidos bajo la presión de la expulsión se les tenía como falsos conversos, asumiendo la idea de que seguían practicando en secreto la fe mosaica.

Por lo menos cien mil de ellos emigraron y engrosaron las comunidades judaicas de Portugal, mediante el pago de un tributo, y otros se refugiaron en el norte de África, Turquía y Europa occidental y oriental. Años más tarde, en 1497, el rey de Portugal decretó la expulsión de todos los judíos residentes en el reino, pero les puso toda suerte de tropiezos para evitar su salida, dado que no quería privarse de estos súbditos de grandes conocimientos y poderosos económicamente.

La diáspora de los judíos sefarditas y posteriormente de los cristianos nuevos portugueses fue de tal índole que arribaron a lugares distantes del continente europeo. Natalie Zemon Davis da cuenta de la presencia de una comunidad de judíos portugueses, banqueros y comerciantes, que se había afincado en Hamburgo con la anuencia del Senado de la ciudad. Con éste firmaron un acuerdo en 1612 permitiéndoles su vecindad. Sin embargo, su vida transcurrió en medio de la tensión y la incertidumbre hasta que parte de los residentes de la ciudad y el clero luterano presionaron para que el Senado adoptara medidas que debilitaran su estancia. Se ordenó el cierre de su sinagoga y el alto costo del impuesto de permanencia hizo que abandonaran la ciudad y se dirigieran a Amsterdam (Zemon Davis, 1999, p 19-20).

La inmigración a Hispanoamérica de los descendientes de estos hebreos antiguos tuvo idéntico origen y se constituyó especialmente de cristianos nuevos portugueses, algunos de ellos con origen remoto español. Se establecieron en lugares de agitado comercio o en remotas regiones viviendo como los de Hamburgo entre la aceptación y el rechazo. Con el pretexto de desobediencia, el rey don Manuel de Portugal ordenó un bautismo forzoso a los judíos si querían permanecer en el país. No obstante, la práctica del judaísmo continuaba firme en este reino, y los que decidieron abandonarlo para evadir la decisión dieron pie a la creencia de que todo portugués que dejara su patria para radicarse en otra parte era judío. En 1543, el Papa autorizó el establecimiento de la Inquisición en

\footnotetext{
${ }^{3}$ Esta propuesta fue utilizada por la autora en la investigación para su libro La diáspora judeo conversa en Colombia siglos XVI y XVII...
} 
Portugal según el modelo español, aunque no resultó eficaz hasta 1580, cuando se unieron la corona española y portuguesa.

Durante esta unificación (1580-1641), la presencia de los portugueses en Hispanoamérica tuvo cierta justificación legal, al ser gobernados por la misma Corona y al firmar con grandes comerciantes portugueses el monopolio en la trata esclavista. A reconocidos portugueses les autorizaron licencias para pasar a las Indias; otros las consiguieron ilícitamente o pagaron por su "composición" una vez establecidos en América, y algunos obtuvieron la naturalización. La unión de los dos reinos hizo posible que muchos portugueses, cristianos nuevos, emigrasen a las Indias o al África, con la intención de alejarse de los tribunales de la Inquisición metropolitanos y dedicarse libremente al comercio de esclavos, de artículos diversos, y al contrabando.

\section{Los portugueses y el comercio esclavista}

El contexto de la "historia Atlántica" es elemento fundamental para el análisis del comercio de africanos esclavizados y de mercaderías llevado a cabo por los grandes traficantes portugueses en el siglo XVII. En este aspecto el "universo" Atlántico se comprende como una unidad histórica en la que los investigadores proponen estudiar los territorios bañados por este océano conceptual y descriptivamente (Law y Mann, 1999, p. 307).

La emergencia de estudios historiográficos de las últimas décadas del siglo XX le ha dado forma a la manera como los historiadores examinan la historia del Atlántico. Con base en este concepto es factible entender las redes y las influencias culturales que circulaban entre el mundo Ibérico, África y las Indias y comprender el desarrollo histórico de los cristianos nuevos portugueses como comunidad que establecía relaciones comerciales y compartía prácticas culturales en un puente que ligaba los tres continentes. Así, las actividades, intereses y perspectivas del tráfico esclavista conectaron el Atlántico. En suma, es posible investigar la diáspora de los cristianos nuevos desde Sefarad hasta las costas africanas y las Indias españolas. De igual manera, judíos portugueses y cristianos nuevos crearon un entramado de relaciones comerciales que unía regiones atlánticas de los imperios portugués y español (Navarrete, 2011, pp.197-198).

El puerto de Cartagena fue uno de los puntos claves de inmigración portuguesa por ser centro autorizado para la recepción de los navíos negreros y una de las paradas obligadas de la flota de Tierra firme en sus viajes de ida y regreso a la Península. Por este motivo, allí se organizaban ferias a las que afluían mercaderes de la región costera, de las diversas provincias interiores y del Nuevo Reino para la compra y recibimiento de mercancías de la metrópoli y de los africanos traídos como esclavizados. En las últimas décadas del siglo XVI y en las primeras del siglo XVII, Cartagena tenía una gran población flotante y unos mil quinientos vecinos. Hacia 1630, los portugueses constituían aproximadamente el diez por ciento de su población. 
Los barcos del tráfico esclavista, es decir, las armazones del registro de esclavos procedentes de África, específicamente, de los ríos de Guinea, Angola, San Tomé y las islas de Cabo Verde, fueron la forma más expedita para el traslado de portugueses a las Indias españolas. Algunos venían como pajes, marineros, grumetes, escribanos de servicio, médicos, cirujanos, boticarios, incluidos en el registro de la nave, lo que les habilitaba para trasladarse en forma legítima. Esto no quería decir que estuvieran facultados para establecerse definitivamente en los puertos a donde arribaban ni adentrarse en el continente; pero muchos de ellos se quedaban sin licencia como pobladores regulares. Otros, sencillamente, venían como pasajeros a quienes los capitanes de los barcos traían con o sin licencia expedida por las autoridades peninsulares.

La opción de ejercer el tráfico esclavista como representantes de los grandes propietarios o acompañante de un lote de esclavos les permitió la posibilidad de trasladarse en estos barcos y afincarse en el Nuevo Mundo. La carga de una armazón no pertenecía a un solo propietario, pues los capitanes, pilotos, marineros, escribanos, cirujanos al servicio de la nave y los pasajeros traían por cuenta propia, o por encargo de otros, varios cautivos como parte de la armazón.

En carta del 30 de agosto de 1630, escrita por el visitador real doctor Antonio Rodríguez de San Isidro dirigida a su majestad, desde Cartagena explicaba las causas por las cuales había tantos portugueses sin licencia, particularmente en este puerto. Según él, se debía a que se trasladaban en los navíos que venían con registro de negros de los ríos de Guinea, despachados por la Casa de Contratación de Sevilla o de Lisboa. A pesar de que la gente de mar y otras personas que viajaban en tales barcos debían volver a los puertos desde donde salían, gran parte de estos navíos se quedaba en las Indias o era vendida. Así mismo, era raro que alguno de los marineros y personas que arribaban en las naves regresasen a su lugar de origen ${ }^{4}$.

Según las ordenanzas del asiento para el tráfico de negros, ningún navío podía traer más de dos personas para el beneficio y venta de los esclavos; sin embargo, eran muchos los que venían bajo este título. Por otra parte, además de los anteriores y de la gente de mar, llegaban en las naves más de veinte personas que argumentaban traer negros de registro y pretendían tener derecho para permanecer en estos territorios por tres años, conforme a las reglas de asiento: "Con que parece que esta tierra brota a montones portugueses y de aquí se esparcen a otras muchas partes sin que parezca hay remedio para estorbarlo..." como decía textualmente el visitador en su carta ${ }^{5}$.

Entre los cristianos nuevos portugueses de Cartagena algunos eran muy ricos, dueños de tierras que detentaban en su poder la masa de los negocios, sin que hubiese contratación y granjería de importancia que no corriese por sus manos;

\footnotetext{
${ }^{4}$ Archivo General de Indias (En adelante AGI). Carta del doctor Antonio Rodríguez de San Isidro Manrique a la Corona. Santa Fe 56B. No. 66.

${ }^{5}$ AGI. Carta del doctor Antonio Rodríguez de San Isidro Manrique a la Corona. Santa Fe 56B. No. 66.
} 
poseían fragatas que navegaban a todos los puertos de las costas de la región y las de México y España llevando y trayendo todo género de frutos de la tierra y mercaderías. Entre ellos estaban quienes tenían carta de naturaleza para permanecer en la Indias, concedida por la Corona 6 .

A finales del siglo XVI y comienzos del XVII, descolló por su caudal y su participación en la sociedad cartagenera Jorge Fernández Gramajo, descendiente de hebreos, quien debió llegar a Cartagena a raíz de la unión dinástica; al poco tiempo tenía acaparado el comercio de esclavos, el de perlas desde el Río de la Hacha y se envolvía en toda suerte de negocios como el envío de tabaco y plata. Poseía varias estancias en las afueras de la ciudad y fue factor de Pedro Gómez Reynel y de los Coutiños, como quien dice, hacía las veces de agente y representante legal en las transacciones del asiento de negros en Cartagena. Mantenía negocios con Lisboa, Flandes, España y puertos africanos; actuó como un verdadero benefactor en las urgencias y necesidades de la provincia; ayudó en la defensa cuando el ataque de Drake; sostuvo hospitales y conventos instituyendo capellanías, y activó la construcción de edificios. Fue amigo personal del presidente de la Audiencia de Santa Fe y de los obispos de Cartagena y Popayán. Cuando dejó como heredero de sus bienes a su sobrino Antonio Núñez Gramajo, su testamento evidenció su gran fortuna, basada en los tres elementos que constituían la riqueza del momento: tierras, casas y esclavos (Vila Vilar, 1977, p. 121-122).

Gran parte de los cristianos nuevos portugueses radicados en Cartagena de Indias, tuvo que ver de una manera u otra con el tráfico de cautivos africanos. Algunos eran representantes directos de los contratos firmados por el rey con el asentista o propietario del asiento, es decir, con el gran comerciante que monopolizaba la trata por un tiempo determinado. Sin embargo, no todos gozaban de los mismos bienes de fortuna; los había de mediano caudal, entretenidos en los oficios profesionales como la medicina, la cirugía y la farmacia y en algunas actividades artesanales de alto rango como la platería. Los más eran "de poco fruto y sustancia en cuanto a caudal". Al respecto decía el visitador Antonio Rodríguez de San Isidro Manrique: "aunque ay algunos con razonable hacienda y caudal, los pobres y miserables son muchos....". La mayor parte era gente miserable -afirmaba en otra misiva el visitador-, de oficio pulperos, arráez, marineros, zapateros o sastres y, otros, sin más ocupación que vagar de una parte a otra careciendo de lugar y morada cierta ${ }^{7}$. Esta era la imagen que de ellos se había formado el visitador Rodríguez de San Isidro Manrique.

Asimismo, puede afirmarse que uno de los grandes ramos de la actividad comercial de la provincia de Cartagena radicó en el comercio de esclavos. Durante el siglo XVII, fue junto con Veracruz uno de los principales puertos habilitados para el desembarque y distribución de esclavos. Es de anotar que Portugal se había constituido en la dueña de los mares de África occidental y por lo tanto del gran

\footnotetext{
${ }^{6}$ AGI. Carta del doctor Antonio Rodríguez de San Isidro Manrique. Santa Fe 56B. No. 67.

${ }^{7}$ AGI. Cartas del doctor Antonio Rodríguez de San Isidro Manrique. Santa Fe 56B. Nos. 66 y 67.
} 
tráfico esclavista. Involucrados en este negocio estaban los judeoconversos portugueses residenciados en Sevilla, Lisboa y sus agentes en la costa africana y en Cartagena.

"Es indudable -dice Enriqueta Vila Vilar- que muchos mercaderes portugueses aparecen en América en relación con el tráfico de esclavos... muchos de ellos se enriquecieron precisamente con este comercio..." (Vila Vilar, 1977, p. 99). Los cristianos nuevos portugueses se convirtieron en una comunidad de gran fortaleza económica y social que monopolizó no sólo el comercio de africanos sino diverso tipo de mercaderías tanto internamente, en las provincias de la Audiencia de Santa Fe, como internacionalmente, en el tráfico con Panamá y Perú.

Como afirma Ricardo Escobar Quevedo:

En el comercio negrero, que era la relación preponderante entre los cristianos nuevos de Cartagena de Indias y de Lima, los roles estaban bien repartidos, de manera que los primeros recibían las cargazones de esclavos, mientras los peruanos se encargaban de su distribución en el sur de la América española (Escobar, 2008, p. 165).

El éxito de los cristianos nuevos y sus parientes sefarditas en la economía atlántica dependió de sus conexiones interoceánicas basadas en la solidaridad mutua y de las redes comerciales que tejieron. En los puertos más importantes se establecía un miembro de la familia que representaba a ésta o a otras familias. Las redes familiares o de amigos intachables fueron el único vehículo confiable para operaciones tan extensas y para garantizar la seguridad monetaria de las transacciones. En el tráfico esclavista y el comercio en general esto era indispensable y explica porqué pudieron sostener el monopolio en el mercado de esclavos a finales del siglo XVI y la primera mitad del XVII. 


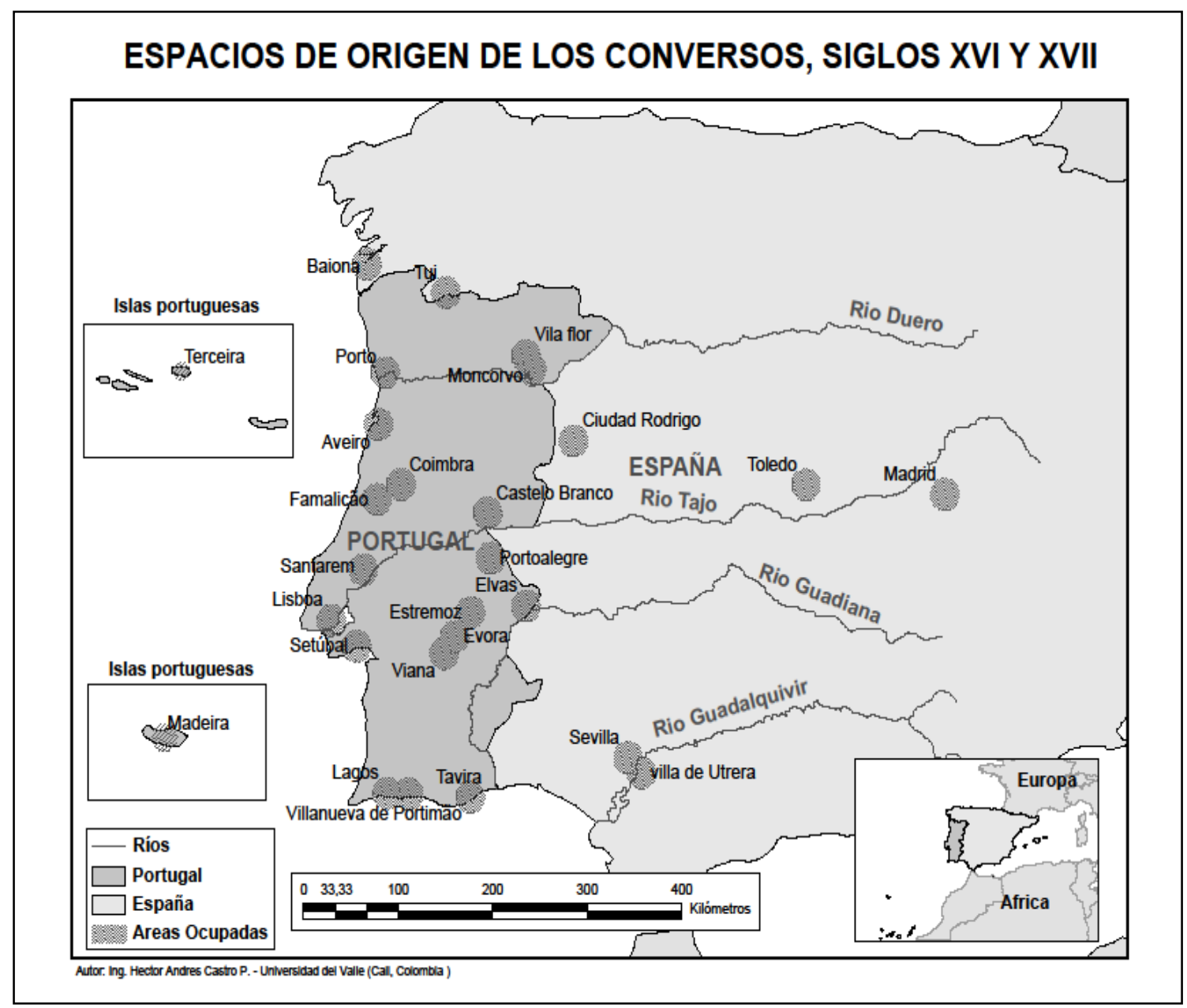

Imagen No. 1.Fuente: Ing. Héctor Andrés Castro P. - Universidad del Valle.

\section{Espacios de origen y destino}

La presencia de los conversos en el Nuevo Mundo fue tan antigua como la conquista española. En ese entonces se trataba de españoles y posteriormente el asunto de los conversos o cristianos nuevos en territorio hispanoamericano fue eminentemente portugués. Es de conocimiento que la entrada de extranjeros a las Indias estaba prohibida, medida amparaba en numerosas leyes restrictivas emanadas por la corona española. Sin embargo, fue un hecho incuestionable el paso de italianos, franceses, flamencos y sobre todo portugueses, al decir de muchos de probable ancestro hebreo durante el siglo XVI y XVII. De allí que la inmigración extranjera a los reinos de Indias estuviera revestida de un evidente carácter clandestino.

Los cristianos nuevos que llegaron a la Audiencia de Santa Fe, a la gobernación de Popayán y a Tierra Firme procedían de numerosas villas, ciudades, aldeas y campos de Portugal, de las islas portuguesas y de la costa occidental africana; otros habían nacido en España y descendían de padres lusitanos. El mayor número de conversos portugueses provenía de Lisboa, Oporto y sus aldeas; 
Villanueva de Portima $\square$ o, Évora y sus aldeas; Coimbra, Portoalegre, Viana do Alentejo, Isla Tercera e Isla de Madeira, Villa de Santarem, Villa de Montemayor y otra serie de villas de varias regiones del Reino de Portugal como el Algarbe. También viajaban de Lagos, Estremoz, Setúbal, Aveiro, Elvas, Tavila; villas y aldeas del arzobispado de Braga, como Altoroso, Famalica $\square$ o, Moncorvo y Villaflor y del obispado de la Guardia, como Castelo Branco y Cubillar. Los conversos procedentes de España, la mayoría de padres portugueses, habían nacido en Sevilla y la villa de Utrera, Islas Canarias, Toledo y sus alrededores, Ciudad Rodrigo y sus aldeas, Baiona y Tui en Galicia y Madrid. También llegó una que otra persona de origen español ${ }^{8}$.

Aunque el primer destino de los cristianos nuevos portugueses en el territorio de la Audiencia santafereña fue Cartagena de Indias, muchos tomaron diversos rumbos y se establecieron en Mompox, Tolú, Santa Marta, Tenerife, Rio de la Hacha, Valle de Upar, Santa Fe de Antioquia, Zaragoza, Cáceres, Victoria, Pamplona, Santa Fe de Bogotá, Salazar de las Palmas, Tunja, Vélez, Remedios, Ubaté, Trinidad, Ibagué, Mariquita, Almaguer, Buga, Cali, Popayán, Pasto y, en Tierra Firme, Portobelo, Villa de los Santos, Nombre de Dios y Panamá. Su presencia fue más representativa en algunas más que en otras, por su número, el tipo de negocios en que se envolvieron y su participación social y política. Sin duda, la ciudad y puerto de Cartagena de Indias concentró una gran comunidad de conversos portugueses ${ }^{9}$.

En esta ciudad se instalaron comerciantes de origen portugués, partícipes del circuito económico de la trata de esclavos, quienes se encargaron de la venta de cautivos en esta ciudad y de su traslado hacia los reinos españoles del continente. Varios de los portugueses asentados en las provincias de Santa Marta, Nuevo Reino, Antioquia y Popayán amasaron grandes fortunas y ocuparon lugar prominente en la sociedad que los albergó, gracias al comercio de esclavos y de productos. Esta actividad les facilitó generar otras fuentes de ingreso que les permitieron mantener una sólida posición económica e incursionar en la política. Algunos también ejercieron profesiones relacionadas con la salud y en Cartagena había médicos, cirujanos y farmaceutas, otros de posición socio-económica inferior, y hasta mercachifles y vagabundos.

\footnotetext{
${ }^{8}$ En el proceso de investigación se identificaron unos setenta lugares de donde procedían sin contar los nacidos en África, pero de origen portugués. Ver mapa Espacios de origen de los conversos en los siglos XVI y XVII.

${ }_{9}^{9}$ Hay constancia en los archivos consultados que ratifica su permanencia en los sitios mencionados. Ver mapa de Lugares de establecimiento.
} 


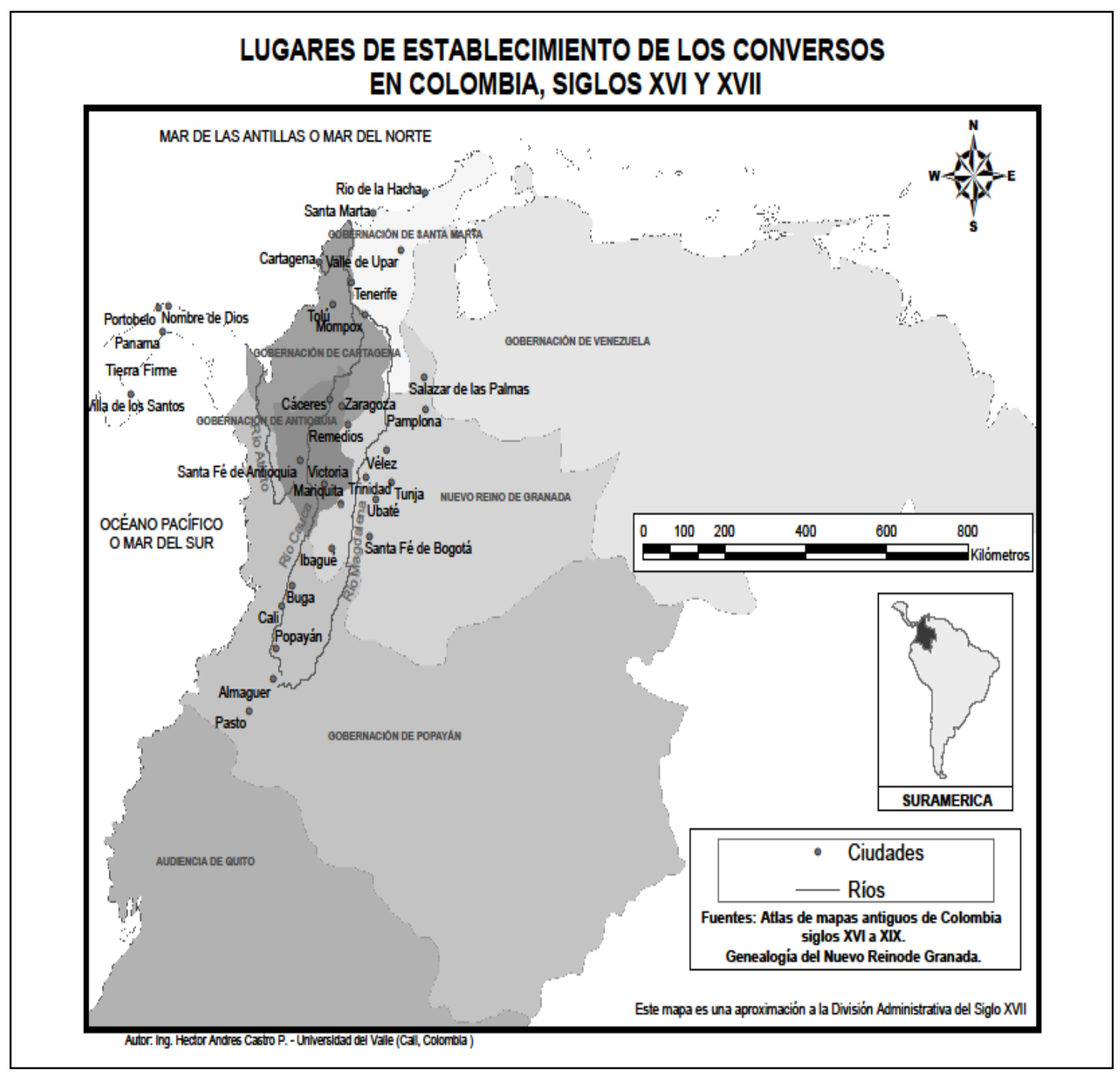

Imagen No. 2. Fuente: Ing. Héctor Andrés Castro P. - Universidad del Valle.

\section{Los cristianos nuevos y las autoridades}

La actuación del tribunal de la Inquisición en España y sus reinos de América contra los cristianos nuevos tenía como uno de sus argumentos la "limpieza de sangre". Hacia 1560 , iniciado el reinado de Felipe ${ }{ }^{10}$, las personas con influencia sobre el monarca expresaban que la heterodoxia en asuntos de fe era un principio de disidencia social y política, y que el tribunal de la Inquisición, institución pública, tendría que convertirse en un organismo político de importancia.

Por esta época hubo protestas en España en oposición a la integración social entre cristianos viejos y nuevos, lo cual se impuso mayoritariamente. Apareció entonces una nueva problemática: "los estatutos de limpieza de sangre" (Pulido,

\footnotetext{
${ }^{10}$ Felipe II reinó de 1556 a 1598.
} 
2003, p. 50), fenómeno debatido, finalizando el siglo, por profesores universitarios, canónigos, abogados de las audiencias, teólogos y corregidores. Muchos creían que la sangre hebrea continuaba vinculada con los preceptos de la ley mosaica y que por lo tanto no era pura. En el proceso que se siguió en el Santo Oficio de Cartagena en 1634 contra Manuel López de Acosta, nacido en Setúbal, Portugal, el inquisidor Martín de Cortázar y Azcárate, al dar su voto en la causa, fue del parecer que el reo, además de ser portugués, de "nación infecta", era descendiente de hebreos por parte de madre, y que esto lo hacía sospechoso de herejía ${ }^{11}$.

El arquetipo socio-cultural se volvía realidad en el hidalgo cristiano viejo, porque en él confluían la sangre que determinaba el linaje noble y la fe religiosa sin mancha de herejía; si además era noble, se convertía en el modelo social. Por ello el cristiano nuevo era un elemento que envilecía los linajes y era proclive a judaizar, pues se afirmaba que el pecado se llevaba en la sangre, dado que la naturaleza estaba viciada. En otras palabras, la limpieza de sangre condicionaba la fe. Tanto la limpieza como la impureza de sangre se transmitían de generación en generación y eran condicionantes para definir la credibilidad de la fe cristiana. Los inquisidores debían averiguar los ancestros de quienes eran sospechosos de judaizar y al probarse que el antepasado había sido un converso, se suponía una descendencia condicionada a la práctica en secreto la fe judaica. En otras palabras, la limpieza de sangre estaba relacionada con la pertenencia a una comunidad religiosa, dado que naturaleza, cultura y raza formaban una alianza inseparable (Navarrete, 2010, pp. 28-29).

En abril de 1653 se hallaban presos en las cárceles de la Inquisición de Cartagena de Indias Rodrigo Téllez, vecino de la ciudad de Santa Fe, y Manuel de Oliveira, vecino de la ciudad de Quito, primos hermanos que habían nacido en Portugal. Estaban encarcelados por el "delito" de judaísmo y fueron testificados de que en la Inquisición de Granada o en la de Córdoba, su abuelo Diego Núñez Batota, de oficio confitero, había sido reconciliado hacia 1544. Entonces sus hijos y parientes huyeron a las Indias y como era necesario conocer sobre esta familia, los inquisidores del tribunal de Cartagena solicitaron a la General Inquisición, en Madrid, pedir a las inquisiciones de Granada y Córdoba relación de la causa de Diego Núñez Batota, con su genealogía inserta, en especial su ascendencia, descendencia y colaterales, y enviarla al Santo Oficio de Cartagena a la mayor brevedad $^{12}$.

Lo anterior demuestra que el tribunal de la Inquisición fue la institución encargada de velar por la pureza de la fe cristiana, sin duda alguna emparentada con la idea de pureza de sangre. Posibles detractores eran los conversos, de quienes se decía provenían de linaje de sangre impura. Desde su instalación en España y posteriormente en los reinos americanos, la función del Santo Oficio fue perseguir todo tipo de herejías, entre ellas la judaizante y los cristianos nuevos

\footnotetext{
${ }^{11}$ Archivo Histórico Nacional de Madrid (En adelante AHNM). Fondo Inquisición. Libro 1020. fls. 442v-443.

${ }^{12}$ AHNM. Fondo Inquisición. Libro 1014. f. 280.
} 
que se trasladaron al Nuevo Mundo fueron víctimas potenciales de estos tribunales. Se tenía el convencimiento de que la mayoría practicaba la fe mosaica en secreto.

Estos cristianos nuevos portugueses, que en las últimas décadas del siglo XVI y la primera mitad del siglo XVII habitaron las provincias de la Audiencia de Santa Fe, Popayán y Tierra Firme pertenecían a distintos estamentos de la sociedad. Algunos de ellos sobresalieron por su fortuna, posición social y poder político; otros se desempeñaron en distintas ramas de la actividad artesanal. Sin embargo, a pesar de su aparente estabilidad residencial, el estatus de extranjeros y, sobre todo, la sospecha de ser descendientes de hebreos, los puso en la mira de las autoridades civiles y eclesiásticas. El rápido enriquecimiento y el pronto ascenso en la burocracia civil, generaron sentimientos de antipatía y envidia entre los vecinos, españoles y criollos, de alto y bajo rango.

Es posible imaginar que en la primera época de su estancia hubieran vivido relativamente tranquilos, en términos religiosos, puesto que el tribunal del Santo Oficio de Lima, del cual dependía el sur del continente, se encontraba lejano y era difícil su identificación y transporte. Cuando en 1610 un nuevo tribunal inquisitorial fue establecido en Cartagena de Indias, el ritmo de sus vidas tuvo un giro desafortunado y el temor llenó de angustia su cotidianidad.

Por otra parte, para la corona española los portugueses siempre tuvieron el carácter de extranjeros incluso durante el tiempo en que las monarquías ibéricas estuvieron unidas (1580-1640). De allí que en diversos momentos de la vida colonial las autoridades metropolitanas enviaran jueces visitadores para averiguar quiénes entre los extranjeros se habían asentado ilegalmente en las distintas gobernaciones de la Audiencia, en Tierra Firme y Popayán, ya fuera para expulsarlos o cobrarles por su composición. Por su entrada de dudosa legitimidad, su probable origen hebreo y dedicación al contrabando, los representantes de las autoridades eclesiásticas y civiles miraron con recelo la llegada de inmigrantes portugueses.

Las composiciones consistían en el pago de cierta cantidad de dinero a cambio de la legitimación de la situación de hecho. Para acceder a la composición y obtener carta de naturaleza se debía ser persona prestante y de caudal. Algunos oficios como el de labrador, boticario y cirujano eran particularmente "útiles a la república" y ameritaban la composición de quienes los desempeñaban como personas de bien.

Con el propósito de identificar y componer a los extranjeros sin licencia para permanecer en las Indias 0 , en caso contrario, expulsarlos, llegó a la ciudad de Cartagena en 1630 el ya mencionado doctor Antonio Rodríguez de San Isidro Manrique, visitador general de la Audiencia de Santa Fe. Este funcionario real inició labores en Cartagena después de ordenar pregones en diferentes "tiempos", invitando a los extranjeros a presentarse para tomarles declaraciones individuales. Con este procedimiento se pretendía averiguar la fecha de entrada en las Indias, 
el tipo de licencia con el que se encontraban, los negocios a los que se dedicaban y el monto de sus caudales ${ }^{13}$.

Uno de los cristianos nuevos portugueses a quien se le concedió el favor de la composición y se le otorgó carta de naturaleza en virtud del "oficio menesteroso" que practicaban en favor de la ciudadanía cartagenera fue Blas de Paz Pinto. Este cirujano, natural de Évora, llegó de Angola en los años veinte de 1600 en un barco que traía registro de esclavos y en el que se desempeñaba como cirujano. Asimismo, traía algunos negros de cuenta propia y por encargo de otras personas. Por habérsele muerto la mayoría de los esclavos, se empobreció y tuvo que quedarse en Cartagena de Indias. En esta ciudad se dedicaba al ejercicio de la cirugía y a "comprar negros enfermos y de deshecho... que sanando los volvía a vender..." ${ }^{14}$ a mejor precio.

Para los conversos, el hecho de poseer fortuna, de ser sospechosos de profesar el judaísmo --de haber llegado clandestina e ilegalmente, en muchos casos, pero sobre todo, por dedicarse a las actividades fraudulentas del contrabando--, hizo que las autoridades peninsulares estuvieran pendientes de sus acciones debido a las pérdidas que ocasionaban a las arcas reales. Aunque las autoridades y la población reconocían su dinamismo económico y precisaban su estancia para abastecer los mercados, los cristianos nuevos permanecían inseguros frente a la ambivalencia de la sociedad marcada por la aceptación y el rechazo. Si bien el grupo de conversos portugueses fue visto con recelo y codicia, ejercieron actividades económicas con el beneplácito de los oficiales reales que aprovecharon la circunstancia para derivar beneficios económicos por medio de sobornos.

La magnitud del problema quedó reflejada en un informe enviado por la Casa de Contratación de Sevilla al Consejo de las Indias, el 15 de junio de 1610. Entre los datos que incluye hacía énfasis en el gran número de portugueses ricos y poderosos que había en Cartagena y en las Indias; de cómo dominaban las voluntades de los gobernadores y ministros y de las pérdidas que causaban a los vasallos de la corona de Castilla, al comercio y a la hacienda real. Según el informe, mandaban con absoluto poder y particularmente en Cartagena eran regidores, alcaldes ordinarios alguaciles mayores y menores y depositarios generales. Venían en navíos de negros o directamente de Portugal y volvían a este reino llevando avisos de todo cuanto ocurría en España y en las Indias. Los portugueses, además de tener en sus manos el comercio de negros, poseían el de todas las granjerías sin escapárseles ninguna y sin pagar derechos en muchos casos, situación que se agravaba al sacar todo el dinero en navíos particulares y llevarlo a Portugal (Chaunu, 1956, pp. 314-315).

Según Hugh Thomas (1997, p.163), los mercaderes españoles acusaban a los judeoconversos portugueses de actuar como ladrones que robaban la plata que

\footnotetext{
${ }^{13}$ AGI. Carta del doctor Antonio Rodríguez de San Isidro Manrique a la Corona. Santa Fe 56B, No. 67.

${ }^{14}$ AGI. Carta del doctor Antonio Rodríguez de San Isidro Manrique a la Corona. Santa Fe 56B, No. 67.
} 
correspondía a España, de ser judíos heréticos que continuaban practicando la fe de Moisés detrás de la máscara del cristianismo y de invadir las Américas con africanos que seguían sus creencias heréticas pero no sólo los cristianos nuevos participaban en el contrabando; también los cristianos viejos lo hacían derivando beneficios de los primeros. En ese entonces, este tipo de comercio no era considerado como una violación ética o moral a las prácticas mercantiles; más bien se le tenía como una parte esencial del mercado debido a las restricciones del régimen imperial. De otro lado, los productos del contrabando eran parte integral de la vida cotidiana de Cartagena en el siglo XVII a pesar del control ejercido por la corona española en la que intervenía la influencia del tribunal de la Inquisición imponiendo su acción en la lucha contra el tráfico ilegal.

Un buen número de cristianos nuevos judaizantes en cantidad de veintiuno, junto con amigos y testigos, cayó en manos de la Inquisición cartagenera, especialmente en las décadas de 1630 y 1640. Se les acusó de participar en una gran conspiración contra el monarca español y la fe cristiana y de estar relacionados con el enemigo holandés. Una conjuración semejante tuvo lugar en Lima, por esa misma época conocida como la "Complicidad Grande". Para la Inquisición eran falsos conversos que habían incurrido en el delito de herejía y confabulado con Holanda por el dominio de los reinos españoles. Padecieron tormentos y castigos infringidos por el tribunal del Santo Oficio; algunos murieron como consecuencia de las torturas, y la mayoría sufrió la pérdida de sus bienes y el destierro de las Indias españolas. Algunos viajaron a España para tratar de recobrar su honra y sus bienes apelando ante la Suprema Inquisición, otros enviaron apoderados en su defensa y esperaron el fallo definitivo en Cartagena; otros más retornaron a Portugal y el resto de cristianos nuevos permanecieron en los territorios de lo que sería posteriormente el virreinato de Nueva Granada guardando un bajo perfil e incorporándose a la sociedad colonial.

La persecución y emigración forzosas de cristianos nuevos portugueses condenados por el Santo Oficio trajeron graves consecuencias al comercio en general, tanto en Lima como en Cartagena. Los españoles y criollos desconocían el mercado Atlántico y las redes internacionales que lo sustentaban. Si bien las arcas reales se abastecieron de caudales, tierras, edificios y esclavos con las confiscaciones a los portugueses, esta riqueza pronto se despilfarró al faltarle el dinamismo mercantil que caracterizó a las redes que tejieron los cristianos nuevos entre los tres continentes atlánticos.

\section{El mundo religioso de los criptojudíos ${ }^{15}$}

El imaginario religioso de los criptojudíos y las representaciones para expresar su necesidad de trascendencia se modificaron al llegar al Nuevo Mundo, donde carecieron de sinagogas, rabinos, escuelas, libros y autoridades religiosas que les permitieran guardar la fe mosaica de acuerdo con la tradición. Entonces crearon

\footnotetext{
${ }^{15}$ El término criptojudío hace referencia a los judíos bautizados como católicos y su descendencia que vivían socialmente como tales, pero secretamente practicaban ritos y costumbres judías.
} 
su propia manera de concebir el judaísmo con respuestas diferentes a las de sus ancestros y sólo pudieron conservar algunos principios, ciertos rituales y el deseo de permanecer fieles a la religión hebraica.

Igualmente, gran número de cristianos nuevos fueron acusados de ejercer la herejía judaizante en secreto. Al preguntarse qué significaba ésta, la misma Inquisición no tenía respuestas claras. Los inquisidores castigaron con rigor lo que creían era judaizar y al no poder precisar lo que entendían como tal, actuaron con criterios distintos, muchas veces confusos. Además existía pluralidad entre los cristianos nuevos en relación con su judaísmo, pues hubo quienes manifestaban abiertamente su pertenencia a la fe mosaica; o conversos que afirmaban no ser cristianos ni tampoco judíos; otros que pretendían ser las dos cosas a la vez, mientras que algunos sostenían que no sabían que cosa era ser judío y conversos de tibio o ferviente cristianismo (Contreras, 1998, pp. 73-74). Otros, más pragmáticos, decían ser judíos en tierra de judíos y cristianos en tierra de cristianos. Existieron quienes vivieron en continua controversia, perplejos y angustiados, tratando de encontrar la fe verdadera. Francisco Rodríguez de Solís, vecino de Cartagena, declaró ante el Santo Oficio de esta ciudad que "muchas veces sintió impulsos de volverse a la ley de Cristo, pero permanecía en la duda cavilando cuál de ambas creencias sería la verdadera" (García de Proodian, 1966, p. 50).

Una cantidad sustancial de judeoconversos no tuvieron otra opción que sostener una identidad dual de cristianos y judíos, característica que acrecentó el establecimiento del tribunal del Santo Oficio. Al mismo tiempo que participaban en las juntas de sinagoga, los cristianos nuevos oían misa, confesaban, comulgaban, guardaban los ayunos y la abstinencia católica, daban limosnas y participaban económicamente en la construcción de hospitales, altares e iglesias. Esto no era óbice para que en la clandestinidad de sus hogares y rodeados de amigos íntimos, mantuvieran algunos preceptos y ritos de la fe de sus ancestros.

La falta de una instrucción constante acompañada de conocedores de la teología hebraica tuvo graves consecuencias en las creencias de los conversos que residieron en las Indias. Sus preceptos no estaban bien cimentados y eran incompletos aunque muchos intentaban conservar la fe de sus ancestros. Los principios fundamentales consistían en la espera del Mesías que algún día llegaría, desconocían por lo tanto a Jesús; Dios era único contrario a la tradición cristiana del Dios unitario y tripartito, y sólo la ley mosaica podía ser el camino correcto para la salvación.

En cuanto a las prácticas religiosas de los criptojudíos, las fuentes documentales indican que observaban el Sabath, el "día Grande" o Yom Quipur, y la fiesta en honor de la reina Esther. La circuncisión no pudo ser guardada con rigor por el peligro que conllevaba su conocimiento y delación ante el Santo Oficio; sólo aquellos que habían viajado por juderías extranjeras estaban circuncisos. También observaban las normas de la dieta judía la cual al igual que el ayuno no eran fáciles de cumplir por los ojos vigilantes de los vecinos curiosos, los esclavos 
domésticos y principalmente los del tribunal de la Inquisición. Para poder preservar esta práctica tuvieron que acudir a innumerables trucos como cocinar cerdo sin comerlo.

El cirujano Blas de Paz Pinto se convirtió en personaje de capital importancia en la comunidad religiosa de cristianos nuevos de Cartagena de Indias. Servía con su oficio a la sociedad en general y era tenido por sus cofrades conversos como hombre docto y entendido en la fe de Moisés, cumplía las veces de maestro de ceremonias en las reuniones de sinagoga que se celebraban en su casa a las que asistía buen número de cristianos nuevos portugueses para celebrar ritos mosaicos. La inquisición lo acusó de transformarse en "capataz de los judíos", en otras palabras, de haber asumido las funciones de rabino y profesor de la ley de Moisés.

Este dirigente natural de la comunidad criptojudía de Cartagena compartía sus conocimientos con sus correligionarios menos entendidos en asuntos de fe o menos dedicados a la observancia y conservación de las creencias y rituales pero deseosos de mantenerse en la fe y la práctica del judaísmo. Tenía entre sus pertenencias libros impresos, entre ellos una Biblia y un libro de oraciones de los cuales leía en los días santos.

En las juntas de sinagoga se explicaba cómo se debía ayunar los viernes y guardar los sábados como fiesta religiosa. Unas veces, antes de la oración, los asistentes cenaban, jugaban a las cartas y después del juego hablaban sobre el cumplimiento del judaísmo y sus bondades. Uno de ellos, entre los más doctos, hacía algunas pláticas sobre las observancia de la fe mosaica ${ }^{16}$.

Existe evidencia documental de que en Santa Fe, capital de la Audiencia del Nuevo Reino, se realizaban igualmente juntas de Sinagoga. Desde septiembre de 1650 estaba pendiente en el tribunal de Cartagena de Indias la causa de Rodrigo Téllez, vecino de la ciudad de Santa Fe; también residía en ella un tío suyo del mismo nombre y un hermano de éste llamado Gaspar Núñez, quien, según un testigo, era el maestro que hacía las veces de rabino y les enseñaba e instruía en la fe mosaica. Rodrigo Téllez el Joven gozaba de buen caudal y poseía tienda de mercader; en su casa vivía su primo Antonio Méndez, que le ayudaba en los negocios y a quien mandó a Holanda con su fortuna con la idea de trasladarse a ese país ${ }^{17}$. Manuel de Olivera, otro cristiano nuevo, integraba esta familia, residió en Santa Fe hacia 1625 en casa de sus tíos Gaspar Núñez y Rodrigo Téllez junto con su hermano Antonio Méndez, y después se trasladó a la ciudad de Quito ${ }^{18}$. Se recibió testimonio de que Rodrigo Téllez participaba con otros en reuniones de

\footnotetext{
${ }^{16}$ Mayores datos sobre la religiosidad y las prácticas y rituales de los criptojudíos pueden encontrarse en el libro La diáspora judeoconversa en Colombia siglos XVI y XVII, pp. 245-288 y en la revista Historia y Espacio $\mathrm{N}^{\mathrm{o}} 18$ (enero-junio de 2002) pp. 61-68 en el artículo de mi autoría "Entre la cruz y la estrella: cristianos nuevos portugueses al norte del Nuevo Reino de Granada".

${ }^{17}$ AHNM. Fondo Inquisición. Libro 1021. fls. 305v-306v y 342-343 y Fondo Inquisición. Libro 1014. Relación de la causa de Rodrigo Téllez. f. 280.

${ }^{18}$ AHNM. Fondo Inquisición. Libro 1021. Relación de la causa de Manuel de Olivera. fls. 307 y 344-348.
} 
criptojudíos celebradas en Santa Fe, en las que hacían sus ritos y ceremonias. Esto demuestra la probabilidad de que en la capital de la Audiencia hubiera un grupo mayor de cristianos nuevos portugueses que se reunían para judaizar.

Con las persecuciones religiosas del tribunal de la Inquisición de Cartagena el sueño de muchos conversos portugueses de las provincias en estudio era abandonar las Indias y sentar residencia en Holanda buscando libertad religiosa y económica al lado de sus congéneres sefarditas. Algunos alcanzaron este sueño pero la mayoría tuvo que permanecer por diferentes razones. En algunos casos sus negocios los obligaron a quedarse, para otros fueron los lazos familiares con miembros de la sociedad nativa, y para los menos afortunados la Inquisición interrumpió sus vidas. Manuel Antonio de Paz, por ejemplo, se había casado con una mestiza; su matrimonio, los negocios y la ceguera que lo afectó al final de su vida no le permitieron tomar rumbo a Flandes. Por su parte, Luis Franco, vecino de Zaragoza, en la provincia de Antioquia, no pudo atender los llamados de su padre desde Flandes porque mucha gente le debía dinero y quizás porque tenía dos hijas naturales, Felipa y María, nacidas de una mujer mulata y no quería abandonarlas, por eso nunca se arriesgó a dejar su casa ${ }^{19}$.

La participación de los cristianos nuevos en la sociedad colonial es un asunto que la historia está en mora de dilucidar. Estudios serios se han efectuado en Brasil, en donde su influencia fue innegable económica y políticamente; otros trabajos se han realizado sobre la actuación de los cristianos nuevos en el virreinato del Perú y en el de México, destacando especialmente los avatares de la familia Carvajal confesa judaizante y unos cuantos relacionados con la gobernación de Buenos Aires, cuyo puerto fue uno de los preferidos como entrada clandestina a la América española. En el territorio de lo que posteriormente sería la república de Colombia, los conversos hicieron presencia en diversas provincias, entre las cuales sobresalió Cartagena por aglutinar una población conversa cuyas actividades determinaron el devenir de esta provincia en los siglos XVI y XVII. Estos correligionarios fueron presa fácil del tribunal de la Inquisición que se instaló allí en 1610, coincidiendo con la época del monopolio portugués del tráfico esclavista. Las fuentes primarias inquisitoriales y civiles permiten concluir que los conversos tejieron redes comerciales entre ellos y sus parientes y amigos sefarditas vecinos de diversas ciudades uniendo los puertos del Atlántico. Con las persecuciones del Santo Oficio cartagenero a mediados del siglo XVII muchos perdieron sus caudales, viajaron a España a reclamar su honra y bienes ante la Suprema Inquisición, mientras que otros regresaron a Portugal y los que se quedaron perdieron los contactos con la comunidad sefardita internacional, mantuvieron un bajo perfil y se integraron a la sociedad colonial.

\footnotetext{
${ }^{19}$ AHNM. Fondo Inquisición. Legajo 1620. Expediente 5. Proceso de fe contra Luis Franco. Legajo 1620. Expediente 6. Proceso de fe contra Pedro López. Testificación de Manuel Antonio de Paz.
} 


\section{BIBLIOGRAFÍA}

\section{Fuentes documentales}

Archivo General de Indias. Fondo Santa Fe No. 66 y 67.

Archivo Histórico Nacional de Madrid. Fondo Inquisición. Libros 1014, 1020, 1021, y legajo 1620.

\section{Fuentes bibliográficas}

Chaunu, Huguette y Pierre (1956). Seville et l'Atlantique (1504-1650). T. IV. Librairie Armand Colin, París.

Contreras Contreras, Jaime (1992). Sotos contra Riquelmes. Regidores, inquisidores y criptojudíos, Anaya, Madrid.

Contreras Contreras, Jaime (1998). "Judíos, judaizantes y conversos en tiempos de la expulsión”. En Historia 16. №. 264. España. Universidad de la Rioja.

Escobar Quevedo, Ricardo (2008). Inquisición y judaizantes en la América española (siglos XVI-XVII). Editorial Universidad del Rosario, Bogotá.

García De Proodian, Lucía (1966). Los judíos en América. CSIC. Madrid.

Law, Robin y Mann, Kristin. (1999) "West Africa in the Atlantic Community: The Case of the Slave Coast". En William and Mary Quaterly. Vol. LVI. № 2.

Navarrete, María Cristina (2002). "Entre la cruz y la estrella: cristianos nuevos portugueses al norte del Nuevo Reino de Granada". En Historia y Espacio № 18. Universidad del Valle. Cali.

Navarrete, María Cristina (1998). "Judaizantes en la colonia. El caso de los portugueses en Cartagena, siglo XVII”. En Revista hispanoamericana. № 24. Fundación Hispanoamericana. Cali.

Navarrete, María Cristina (2002) "Judeo-conversos en la Audiencia del Nuevo Reino de Granada, siglos XVI y XVII”. Historia Crítica. № 23. Universidad de los Andes. Bogotá.

Navarrete, María Cristina (2010) La diáspora judeoconversa en Colombia siglos XVI y XVII. Incertidumbres de su arribo, establecimiento y persecución. Programa Editorial Universidad del Valle. Cali.

Navarrete, María Cristina (2011) "Judeoconversos en el Nuevo Reino de Granada siglos XVI y XVII”. En Los judíos en Colombia. Una aproximación histórica. Casa Sefarad. Madrid. 
Pulido Serrano, Juan Ignacio (2003). Los conversos en España y Portugal. Arco Libros S. L., Madrid.

Thomas, Hugh (1997). The Slave Trade. Simon and Schuster, Nueva York.

Vila Vilar, Enriqueta (1977), Hispanoamérica y el Comercio de Esclavos. Escuela de Estudios Hispano-americanos, Sevilla.

Zemon Davis, Natalie (1999), Mujeres de los márgenes. Tres vidas del siglo XVII. Edicones Cátedra, Madrid.

Recibido: Febrero 4 de 2011

Aprobado: Mayo 9 de 2011 